\title{
Evaluating Surface Variables Simulated by the North American Regional Climate Change Assessment Program over the Great Lakes Region
}

Lingli $\mathrm{He}^{*}$

Department of Civil and Environmental Engineering, University of Michigan, Ann Arbor, MI, USA

*Corresponding author: Lingli He, Department of Civil and Environmental Engineering, University of Michigan, Ann Arbor, MI, USA, Tel: (734) 763-4461; E-mail: linglihe@umich.edu

Received date: Mar 20, 2016; Accepted date: Apr 11, 2016; Published date: Apr 18, 2016

Copyright: (c) $2016 \mathrm{He} \mathrm{L}$. This is an open-access article distributed under the terms of the Creative Commons Attribution License, which permits unrestricted use, distribution, and reproduction in any medium, provided the original author and source are credited.

\begin{abstract}
The Great Lakes Region as important resources for water usages plays an important role in the U.S. economy. As the area might be susceptible to global warming, well-informed decisions in response to the possible global warming effects depend on accurate regional assessments by climate models such as Regional Climate Models (RCMs). Four historical RCM runs from the North American Regional Climate Change Assessment Program (NARCCAP) were chosen to study the reliability of simulated land surface variables such as latent heat, sensible heat, surface air temperature, soil moisture, and runoff. The Global Land Data Assimilation System (GLDAS) was used as a truth dataset to evaluate the biases of the RCM results. The comparisons of the monthly climatology of the energy components and water budget components simulated by the RCMs and GLDAS showed that, latent heat and skin air temperature by RCMs were close to the truth data, large biases were identified for sensible heat and runoff values. Specifically, the Weather Research and Forecasting Model (WRFG) model, which used the same Noah land scheme as in GLDAS, showed positive biases of down-welling radiation, sensible heat, and surface air temperature. The Canadian Regional Climate Model version 4 (CRCM) model was found to have lower soil water content, larger snow amount, and more snow melt than the truth data. The results from this study provide a certain degree of confidence for other studies concerning the Great Lakes region to interpret the future predictions of latent heat and air temperatures by the NARCCAP project. Meanwhile, caution should be taken to review and utilize the simulated results related to soil moisture or runoff. This study also provides insights and direction for RCM model developers to further refine related modeling parameterizations.
\end{abstract}

Keywords: Climate change; Great Lakes; RCM; GCM; North American regional climate change assessment program (NARCCAP); Global land data assimilation system (GLDAS)

\section{Introduction}

The Great Lakes region, as the largest fresh water body in the world, is regarded as a major resource for water usages (e.g., drinking, irrigation, shipping, ecological habits, hydropower, and recreation) and plays an important role in the U.S. economy [1,2]. The Great Lakes region might be susceptible to the effect of global warming, as the changes of climate condition could influence the surface energy partition and water cycle, further affecting Great Lakes water level $[3,4]$. Reliable projections of land-surface processes are therefore required to make well-informed decisions in response to future climate change [5,6]. Currently, various assessments on the potential impacts of global climate change on the Great Lakes region have been focused on climate projections from General Circulation Models (GCMs) [7,8]. However, GCMs usually have a resolution of 200-300 km, which is inadequate to resolve the spatial details (e.g., topography, vegetation, soils, lakes, and shorelines) and therefore unable to adequately represent regional assessments. Regional Climate Models (RCMs), which provides finer spatial resolution than GCMs, provide one possible solution to resolve regional variability. Although same principles of physics, chemistry, and fluid dynamics are employed in RCMs or GCMs, different formulations, parameterizations, and boundary conditions in models lead to different projections [9-11].
The North American Regional Climate Change Assessment Program (NARCCAP) has attempted to produce multiple RCM simulations as an ensemble over the continental U.S. with different GCM hosts providing boundary conditions [12-21]. The historical and future runs of RCMs from the NARCCARP program have been used to evaluate effects of climate change on variables such as surface temperature, runoff and snow water equivalent [21]. Increasing ground and satellite-based observations or reanalyzed datasets of surface energy fluxes have enabled the validation of RCMs or GCMs, especially the energy partitioning processes [22]. Particularly, the Global Land Data Assimilation System (GLDAS) assimilates various observation data and generated global land surface variables by using land surface schemes uncoupled with atmospheric models [23-25]. The GLDAS is therefore not affected by possible biases introduced by numerical weather predication model and provides a relatively reliable gridded dataset to evaluate the climate model simulation results.

The focus of this study is to evaluate the simulated land surface variables in energy partition process or in the water cycle (such as latent heat, sensible heat, surface air temperature, soil moisture, and run-off) by different RCMs in the NARCCAP archive. The historical runs of the RCMs were compared with the reanalysis dataset from GLDAS over the Great Lakes Region. The results about the accuracy of those RCMs from this study provide a certain degree of confidence for other studies concerning the Great Lakes region to interpret the future predictions of those land surface variables by the NARCCAP project. Meanwhile, caution should be taken to review and utilize the simulated results of those RCMs. This study also provides insights and direction 
for RCM model developers to further refine related modelling parameterizations.

\section{Data and Methods}

\section{Data}

GLDAS: The goal of the Global Land Data Assimilation System (GLDAS) is to ingest satellite- and ground-based observational data products and to generate optimal fields of land surface states and fluxes [25]. Specifically, the GLDAS consists of land-surface models forced with observations such as precipitation gauge observations, satellite data, and radar precipitation measurements. The GLDAS has been implemented using existing Surface Vegetation Atmosphere Transfer Schemes (SVATS) at $1 / 4$ th degree resolution globally by multiple research institutes in the United States: National Oceanic and Atmospheric Administration (NOAA), National Aeronautics and Space Administration's Goddard Space Flight Center (NASA/GSFC), National Center for Atmospheric Research (NCAR), Princeton University, and the University of Washington. As the used land-surface schemes are uncoupled from atmospheric models, the GLDAS outputs are not affected by numerical weather prediction biases. Model parameters are derived from the existing high-resolution vegetation and soil coverage. With data assimilation techniques, remotely-sensed or in situ observations such as soil moisture, temperature, snow, evaporation, sensible heat flux, and runoff were used to further validate and constrain the GLDAS predictions. The project has resulted in a massive archive of modeled and observed, global, surface meteorological data, parameter maps, and outputs which includes 1979 present simulations of the Noah, CLM, VIC and Mosaic land surface models.

This study chose the monthly outputs from the GLDAS as the reanalyzed observation data to evaluate the performance of RCMs from NARCCAP. The downloaded data are from the Noah land surface model driven by gridded precipitation, temperature, and wind time series, as well as downward solar and long wave radiation. The outputs variables included latent heat $(\mathrm{LH})$, sensible heat $(\mathrm{SH})$, ground heat (G), surface air temperature (TS), total soil moisture content (SM), precipitation, snowfall, surface down-welling shortwave, and surface down-welling long wave. The outputs are in regular grids, with the grids dimension of $150 \times 360$. As the accuracy of the data at lake or sea surfaces were not guaranteed, those areas have been masked out from the output data.

NARCCAP: The general NARCCAP strategy consists of two phases (Table 1). In Phase I, six RCMs were forced with global reanalysis from the National Center Environmental Prediction (NCEP) reanalysis [26] as boundary conditions, and 25 year (1980-2004) RCM simulations were implemented. In Phase II, RCMs were driven by GCMs outputs as boundary conditions for both historical and future scenarios. For the historical runs, 30 year (1971-2000) RCM simulations were carried out. For the scope of this study, two RCM models were chosen: the Canadian Regional Climate Model version 4 (CRCM) and the Weather Research and Forecasting Model (WRFG). Two boundary conditions were selected: the NCEP boundary condition in Phase I, and the Third Generation Coupled Global Climate Model (CGCM3) boundary condition for the historical run from Phase II. Therefore, 4 RCM runs in total were examined in this study: CRCM-NCEP, CRCM-CGCM3, WRFG-NCEP, and WRFG-CGCM3.
The outputs of the variables of interest are available as 3 hourly average or sum values. The examined variables include latent heat, sensible heat, surface air temperate, total soil moisture content, surface runoff, subsurface runoff, precipitation, snowfall, snow melt, snow water equivalent, total soil frozen moisture content, surface downwelling shortwave, surface up-welling shortwave, surface down-welling long wave, and surface up-welling long wave. Among four RCM runs, the WRFG-NCEP run lacks the data of surface upwelling shortwave, surface down-welling long wave, and surface upwelling long wave values.

\begin{tabular}{|l|l|l|l|l|l|}
\hline \multicolumn{7}{|l|}{ Phase I } & \multicolumn{2}{l}{ Phase II } \\
\hline & NCEP & GFDL & CGCM3 & HADCM3 & CCSM \\
\hline CRCM & finished & - & finished & - & finished \\
\hline ECP2 & finished & finished & - & finished & - \\
\hline HRM3 & finished & finished & - & finished & - \\
\hline MM5I & finished & - & - & finished & finished \\
\hline RCM3 & finished & finished & finished & - & - \\
\hline WRFG & finished & - & finished & - & finished \\
\hline & & & & & \\
\hline Time slices & & finished & - & - & finished \\
\hline
\end{tabular}

Table 1: Status of NARCCAP archived RCM/GCM combinations.

The CRCM model has polar stereographic grids (with grids dimension of $115 \times 140$ ); the WRFG has the Lambert projection (with grids dimension of $109 \times 134$ ).

\section{Methods}

The Great Lake region is identified as an area with longitude in the range of $\left[96.3^{\circ} \mathrm{W}, 73.3^{\circ} \mathrm{W}\right]$ and the latitude in the range of $\left[36.8^{\circ} \mathrm{N}\right.$, $\left.57.8^{\circ} \mathrm{N}\right]$ (Figure 1).

As GLDAS, CRCM, and WRFG model schemes have different grids, to facilitate direct comparison with GLDAS data, the CRCM and WRFG data were projected to the same regular grids as in GLDAS. To have the same geographical coverage for evaluation, the areas of lakes were masked out in CRCM and WRFG as in GLDAS. The 20 year time period (1980-1999) was chosen for the GLDAS or NARCCAP data, according to the data availability.

The output values concerning the water cycle and the energy partition process from CRCM and WRFG were transformed to be having the same physical meaning and units as compared to those in GLDAS data. Specifically, runoff values were calculated as the sum of surface and subsurface runoff, precipitation values were computed as the sum of snowfall rate and liquid phase precipitation. Volumetric soil moisture values ([mm water $/ \mathrm{mm}$ soil $]$ ) were calculated as the total soil moisture content ([mm water]) divided by the soil column depth ([mm soil]). In particular, the GLDAS uses Noah land surface scheme and represents soil as 4 layers: 0-0.1 m, 0.1-0.4 m, 0.4-1.0 m, and 1.0-2.0 m. The CRCM uses CLASS 2.7 land surface scheme and has three soil layers, with thicknesses of $0.1 \mathrm{~m}, 0.25 \mathrm{~m}$, and $3.75 \mathrm{~m}$, respectively [27]. The WRFG used the same Noah land surface model as the GLDAS; therefore the total soil depth in the WRFG is also $2 \mathrm{~m}$. 
Citation: He L (2016) Evaluating Surface Variables Simulated by the North American Regional Climate Change Assessment Program over the Great Lakes Region. J Climatol Weather Forecasting 4: 160. doi:10.4172/2332-2594.1000160

Page 3 of 6

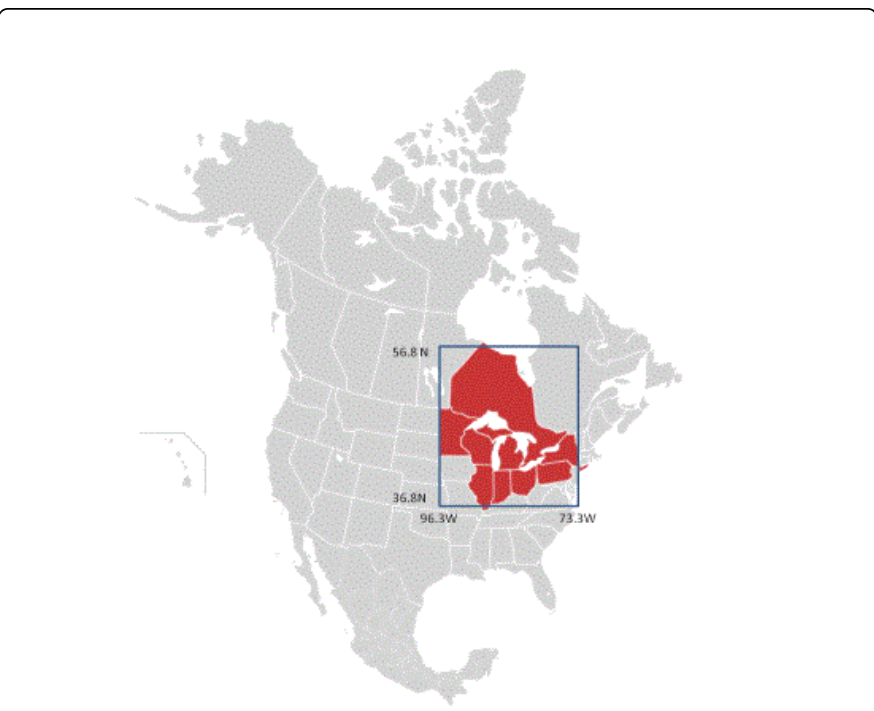

Figure 1: The location of the Great Lakes region (red area), the chosen area for analysis (blue box) and its longitude and latitude.

As land surface fluxes are strongly influenced by the amount of available energy such as net radiation, the examination of differed net radiation among models is necessary. However, net radiation () values are not explicitly outputted by the GLDAS or the NARCCAP simulations. According to the data availability of energy components, the net radiation in GLDAS and NARCCAP were calculated by Eqn (1) and Eqn (2), respectively:

$$
\begin{aligned}
& \mathrm{R}_{\mathrm{n}}=\mathrm{LH}+\mathrm{SH}+\mathrm{G} \\
& \mathrm{R}_{\mathrm{n}}=\left(\mathrm{SW}_{\text {down }}-\mathrm{SW}_{\text {up }}\right)+\left(\mathrm{LW}_{\text {down }}-\mathrm{LW}_{\text {up }}\right)
\end{aligned}
$$

where $\mathrm{LH}, \mathrm{SH}$, and $\mathrm{G}$ are the latent heat, sensible heat, and ground heat, given in the GLDAS output dataset; $\mathrm{SW}_{\mathrm{down}}, \mathrm{SW}_{\mathrm{up}}, \mathrm{LW}_{\mathrm{down}}$, and $\mathrm{LW}_{\text {up }}$ are surface down-welling shortwave, surface upwelling shortwave, surface down-welling long wave, and surface upwelling long wave radiations given in NARCCAP output dataset. As the WRFG-NCEP run lacks radiation data, the net radiation was only computed for other three runs (i.e., CRCM-NCEP, CRCM-CGCM3, and WRFG-CGCM3).

All the simulated variables during the chosen 20 year time slice were processed to have monthly mean values. The energy components and water budget components were spatially averaged over the Great Lakes Region. The monthly time series and monthly climatology was generated accordingly. In particular, the partition ratio of net radiation into latent heat was calculated by dividing the monthly climatology values of net radiation by the monthly climatology of latent heat. The partition ratio of net radiation into sensible heat was also calculated in the same way. Extensive discussions have been focused on the monthly climatology of above-mentioned variables. Spatial distribution of variables for the June, July, and August (JJA) seasonal mean was plotted to have a general idea of the spatial differences among datasets. Figures of the spatial distribution of variables and monthly time series were attached in (Appendices I and II).

\section{Results and Discussion}

\section{Energy components}

Latent heat: As shown in Figure 2a, the monthly climatology of LH for GLDAS, WRFG-NCEP, WRFG-CGCM3, CRCM-NCEP, and CRCM-CGCM3 are fairly consistent. The GLDAS has the largest magnitude of LH year long, WRFG-CGCM3 and WRFG-NCEP tend to underestimate $\mathrm{LH}$ for the summer time, CRCM-CGCM3 and CRCM-NCEP tend to underestimate LH for both the summer and winter time. The simulation results of WRFG-CGCM3 and WRFGNCEP (or CRCM-CGCM3 and CRCM-NCEP) are nearly identical. In other words, the differences of variables (i.e., $\mathrm{LH}, \mathrm{SH}$, and etc.) simulated by the same model driven by different boundary conditions are smaller than the discrepancies of variables simulated by different RCMs. This might suggest that the variability of simulation results mainly arise from different modelling scheme and parameterizations (i.e., WRFG or CRCM) rather than the differences of boundary driving forces (i.e., NCEP or CGCM3).
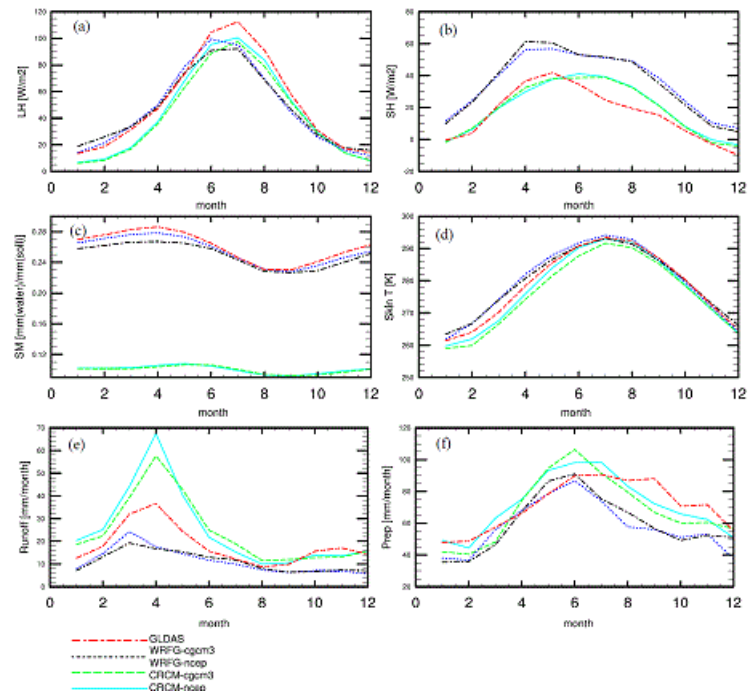

Figure 2: The monthly climatology of latent heat $(\mathrm{LH}, \mathrm{a})$, sensible heat $(\mathrm{SH}, \mathrm{b})$, volumetric soil moisture $(\mathrm{SM}, \mathrm{c})$, skin air temperature (Skin T, d), runoff (e), and precipitation ( $\mathrm{f}$ ) over the period of $1980 / 1981$ to $1999 / 2012$.

Sensible heat: The WRFG model (driven by NCEP or CGCM3) has the largest magnitude of $\mathrm{SH}$, and is 50\% larger than GLDAS (Figure $2 \mathrm{~b}$ ), although their surface soil temperatures are similar (as indicated by the surface air temperature in Figure 2d). As WRFG and GLDAS used the same Noah land surface scheme, it is not surprising that they have similar seasonal cycles, i.e., the same peaks and 'falls'. As the absolute magnitude of $\mathrm{LH}$ or $\mathrm{SH}$ is depending on the partition of available energy, to explain the differences of $\mathrm{SH}$ among models, it is necessary to compare their net radiation.

Net radiation: The net radiation of CRCM and GLDAS are surprisingly consistent (Figure 3 ). The WRFG model has a larger net radiation than other three datasets, mostly because of larger surface down-welling shortwave (Figure 3a), smaller reflected shortwave (Figure $3 \mathrm{~b}$ ), and smaller amount of upwelling long wave (Figure $3 \mathrm{~d}$ ). 
Citation: He L (2016) Evaluating Surface Variables Simulated by the North American Regional Climate Change Assessment Program over the Great Lakes Region. J Climatol Weather Forecasting 4: 160. doi:10.4172/2332-2594.1000160

Page 4 of 6

The different surface down-welling shortwave is probably due to the differences introduced by the atmospheric schemes.
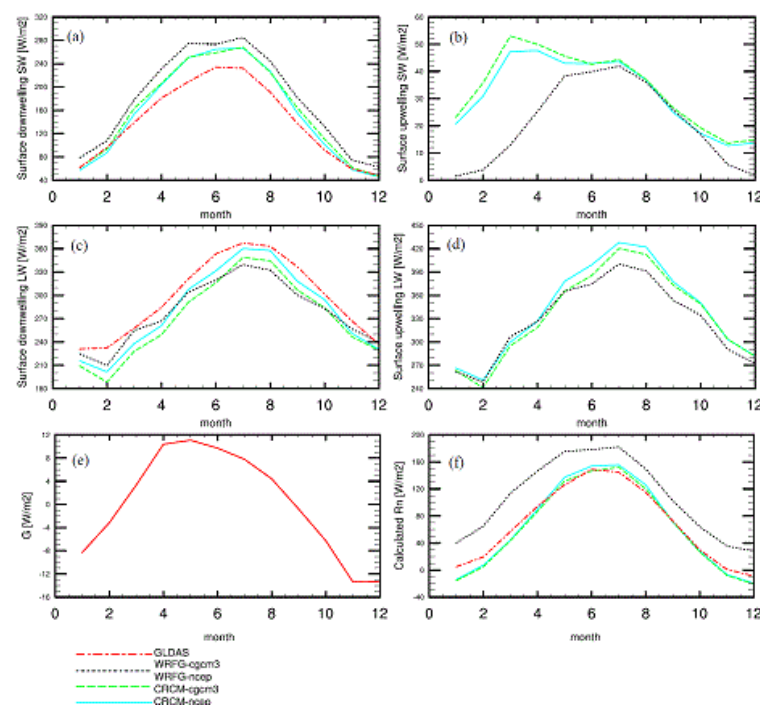

Figure 3: The monthly climatology of surface down-welling shortwave (a), surface upwelling shortwave (b), surface downwelling long wave $(\mathrm{c})$, surface upwelling long wave (d), ground heat (e), and calculated net radiation (f) over the period of $1980 / 1981$ to $1999 / 2012$.

The WRFG model tends to partition more energy to $\mathrm{SH}$ and less energy to LH as compared with the CRCM model and GLDAS (Figures $4 \mathrm{a}$ and $4 \mathrm{~b}$ ). The larger $\mathrm{SH}$ partition ratio, combined with larger amount of net radiation by WRFG, contributed to the larger magnitude of SH in WRFG than other datasets. These conclusions support some inferences by Lu and Kueppers [22]. In their study, the standard WRF simulation tends to have a warmer bias, which caused overestimated net radiation and positive biases in sensible heat, latent heat, and surface temperature compared with ground-based observations. In our study, the net radiation, sensible heat, and surface air temperature from the WRFG indeed showed positive biases compared with the GLDAS data. The latent heat of the WRFG, however, is slightly larger than GLDAS only during winter and spring time, but is smaller than GLDAS for the summer and autumn. Those positive biases were believed to be caused by modules other than the land surface scheme, as an improved simulated downward solar radiation has shown to reduce the biases of simulated energy fluxes and temperature [22].

\section{Water budget components}

Volumetric soil moisture: Soil moisture is an important component and a key mediator between land surface and atmospheric interactions. Soil moisture can constrain LH directly through surface evaporation and transpiration when soil water is limited. The soil moisture can also regulate partitioning of precipitation into runoff and sub-surface water storage.
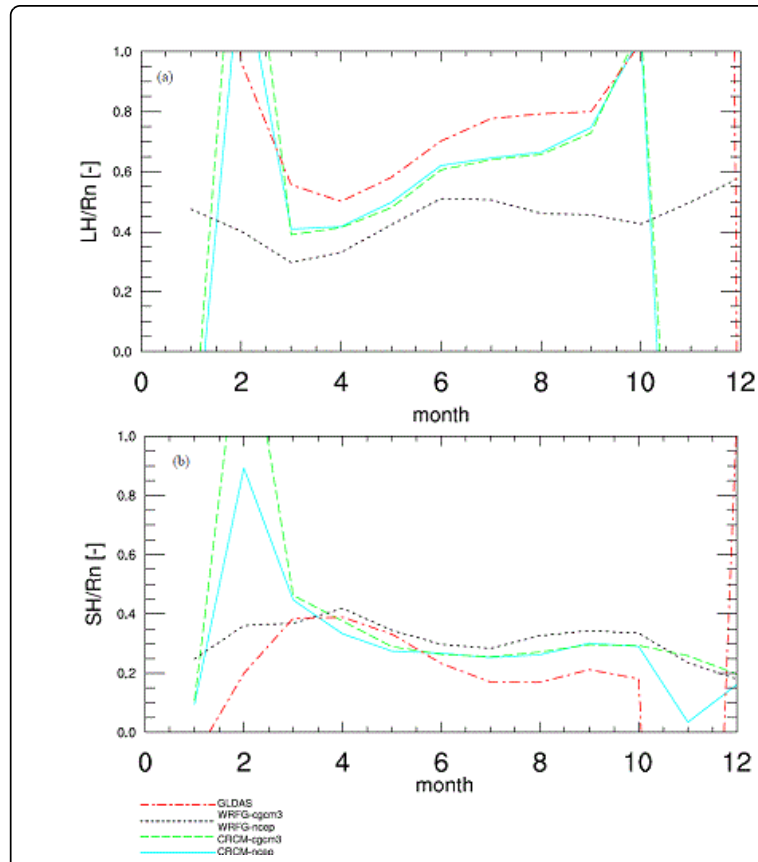

Figure 4: The monthly climatology of the energy partition ratio of LH (a) and SH (b) over the period of 1980/1981 to 1999/2012. Note that for winter time, the CRCM and GLDAS models have near-zero $\mathrm{Rn}$ values, therefore the partition ratio of $\mathrm{LH}$ or $\mathrm{SH}$ might be higher than one. The comparison of the partition ratio only focused on the time period of March to September.

The volumetric soil moisture by WRFG and GLDAS agree very well (Figure 2c), again probably due to the same land surface scheme and soil layers in two models. As the soil water level are the same in the WRFG and GLDAS, the soil moisture is thus not a reason for the different partition ratio of SH (and LH) in WRFG and GLDAS. The CRCM has a very low value of soil moisture year-long. The differences of soil moisture by CRCM can be attributed to several reasons. First, as soil moisture is a state variable that could 'memorize' previous soil wetness state, different initial soil moisture values might influence subsequent magnitudes. CRCM has lower soil water content probably because it was initialized with a smaller value to begin with. Second, different soil properties might have been used in CRCM, a very sandy soil property could induce very low filed capacity and low SM values. Third, precipitation might be a factor in general; however, precipitation in CRCM is larger than other models (Figure 2f) and therefore is not contributing to the smaller SM in CRCM for this case.

Runoff: Runoff by CRCM is the largest among RCMs and GLDAS, especially for the spring time period (Figure 2e). This is mostly due to larger snow melt in spring time period (Figure 5a). The larger snow melt is further because of more snow predicted in the CRCM in the winter time (Figure $5 \mathrm{c}$ ), probably because the model parameters were tuned to simulate more snow according to the general snow condition in Canada. The differences of soil frozen water content among models can be safely neglected. The more snow in winter time in CRCM has caused more surface upwelling shortwave than other models because of the high albedo values of snow (Figure $3 b$ ). 

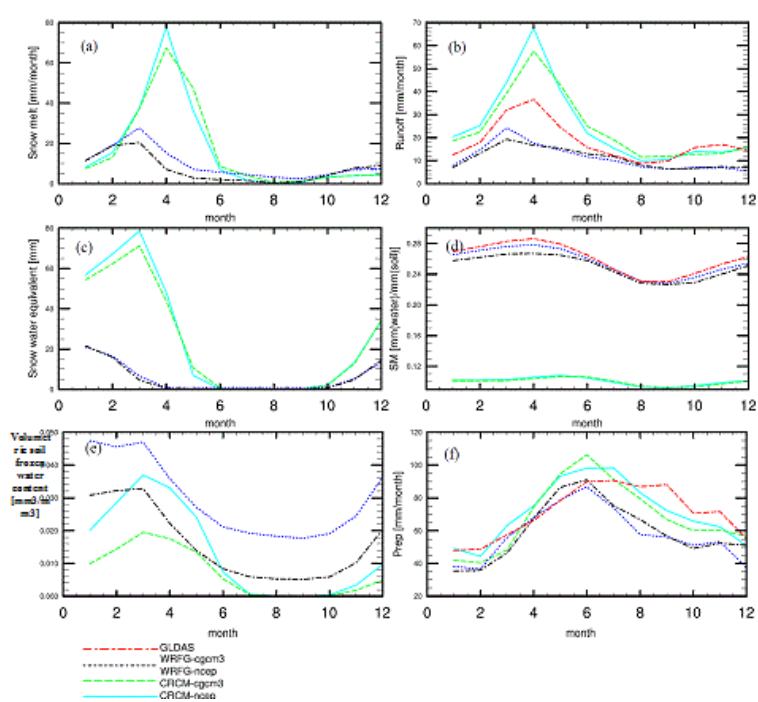

Figure 5: The monthly climatology of surface snow melt (a), runoff (b), snow water equivalent (c), volumetric soil moisture (d), volumetric soil frozen water content (e), and precipitation (f) over the period of 1980/1981 to $1999 / 2012$

\section{Spatial patterns}

Spatial distribution of latent heat, sensible heat, surface air temperature, soil moisture, runoff, and precipitation were plotted for the averaged JJA season over the 20 years (Appendix I). No quantitative analysis has been conducted to evaluate the spatial differences so far, but will be included in future works.

\section{Summary and Conclusion}

This study examined 20-yr outputs from four historical RCM runs (CRCM-NCEP, CRCM-CGCM3, WRFG-NCEP, and WRFG-CGCM3) in the NARCCAP project. The RCMs outputs were compared with the reanalyzed dataset GLDAS. The monthly climatology of energy components and water budget variables were examined. Outputs from those four RCM runs and GLDAS give consistent latent heat and skin air temperatures, but their simulation results vary with different extent for sensible heat and runoff. Variabilities of RCMs simulation results are mainly caused by different modeling parameterizations (i.e., CRCM or WRFG), rather than boundary conditions (i.e., NCEP or CGCM3). The CRCM model usually give low soil moisture values, larger snow melt rate, and more runoff in spring time as more snow is predicted in winter time than other models. Sensitivity studies by other researchers suggest that the CRCM projections show strong sensitivity to changes of configuration or physical parameterization $[28,29]$ and that the uncertainty in the CRCM's internal variability must be assessed to provide suitable regional hydrological responses to climate change [30].

As the GLDAS and WRFG are all driven by Noah land surface model, it is expected that they show consistent outputs (e.g., soil moisture). However, WRFG and GLDAS have differed magnitude of net radiation and of course its subsequent partition to latent heat and sensible heat, probably because of different atmospheric modules. Meanwhile, other researchers showed that there are great variations in the historical and future climate projections of the United States (including the Great Lakes area) among the NARCCAP RCMs, which illustrate the importance of further investigations of key process and parameterizations in those modules [20,31,32].

The results from this study provide a certain degree of confidence for other studies concerning the Great Lakes region to interpret the future predictions of latent heat and air temperatures by the NARCCAP project. Meanwhile, caution should be taken to review and utilize the simulated results related to soil moisture or runoff. This study also provides insights and direction for RCM model developers to further refine related modeling parameterizations.

\section{Acknowledgement}

Lingli He was supported by the Marian Sarah Parker Award and the Rackham International Students Fellowship at the University of Michigan. This work was a project for AOSS 588 (Winter 2012) led by Prof. Allison Steiner at the University of Michigan.

\section{References}

1. Laurent KL, Scavia D, Friedman KB, Krantzberg GK, Creed IF (2015) Critical forces defining alternative futures for the Great Lakes-St. Lawrence River basin. J of Great Lakes Research 41: 131-138.

2. Michalak AM, Anderson EJ, Beletsky D, Boland S, Bosch NS, et al. (2013) Record-setting algal bloom in Lake Erie caused by agricultural and meteorological trends consistent with expected future conditions. Proc Natl Acad Sci 110: 6448-6452.

3. Bartolai AM, He Lingli, Ardith E (2015) Climate change as a driver of change in the Great Lakes St. Lawrence River Basin. Journal of Great Lakes Research 41: 45-58.

4. Mortsch LD, Quinn FH (1996) Climate change scenarios for Great Lakes Basin ecosystem studies, Limnology and oceanography 41: 903-911.

5. King GW, Lindroth RL (2003) Confronting climate change in the Great Lakes region.

6. Hayhoe K, VanDorn J, Croley T, Schlegal N, Wuebbles D (2010) Regional climate change projections for Chicago and the US Great Lakes, Journal of Great Lakes Research 36: 7-21.

7. Karl TR, Melillo JM, Peterson TC (2009) Global Climate Change Impacts in the United States: Cambridge University Press.

8. Lofgren BM, Quinn FH, Clites AH, Assel RA, Eberhardt AJ, et al.( 2002) Evaluation of potential impacts on Great Lakes water resources based on climate scenarios of two GCMs, Journal of Great Lakes Research 28: 537-554.

9. Diallo I, Sylla M, Giorgi F, Gaye A, Camara M (2012) Multimodel GCMRCM ensemble-based projections of temperature and precipitation over West Africa for the early 21st century, International Journal of Geophysics 1-19.

10. Kendon EJ, Jones RG, Kjellström E, Murphy JM (2010) Using and designing GCM-RCM ensemble regional climate projections. Journal of Climate 23: 6485-6503.

11. Gao X, Shi Y, Song R, Giorgi F, Wang Y et al. (2008) Reduction of future monsoon precipitation over China: Comparison between a high resolution RCM simulation and the driving GCM. Meteorology and Atmospheric Physics 100: 73-86.

12. Gutowski WJ, Arritt RW, Kawazoe S, Flory DM, Takle ES, et al. (2010) Regional Extreme Monthly Precipitation Simulated by NARCCAP RCMs. Journal of Hydrometeorology 11: 1373-1379.

13. Mearns LO, Gutowski WJ, Jones R, Leung LY, McGinnis S, et al. (2009) A regional climate change assessment program for North America. Eos Trans Amer Geophys Union 90: 311-312. 
Citation: He L (2016) Evaluating Surface Variables Simulated by the North American Regional Climate Change Assessment Program over the Great Lakes Region. J Climatol Weather Forecasting 4: 160. doi:10.4172/2332-2594.1000160

Page 6 of 6

14. Bukovsky MS, Gochis DJ, Mearns LO (2013) Towards assessing NARCCAP regional climate model credibility for the North American Monsoon: Current climate simulations. Journal of Climate 26: 8802-8826.

15. Alexander MA, Scott JD, Mahoney K, Barsugli J (2013) Greenhouse GasInduced Changes in Summer Precipitation over Colorado in NARCCAP Regional Climate Models. Journal of Climate 26: 8690-8697.

16. Elguindi N, Grundstein A (2013) An integrated approach to assessing 21st century climate change over the contiguous US using the NARCCAP RCM output. Climatic change 117: 809-827.

17. He L, Steiner A, Ivanov V (2013) Evaluating land surface climate and hydrological variables simulated by NARCCAP over the Great Lake Region and implication of climate change.

18. Kang EL, Cressie N (2013) Bayesian hierarchical ANOVA of regional climate-change projections from NARCCAP Phase II, International Journal of Applied Earth Observation and Geoinformation 22: 3-15.

19. Mearns L, Sain S, Leung L, Bukovsky M, McGinnis S, et al. (2013) Climate change projections of the North American regional climate change assessment program (NARCCAP). Climatic Change 120: 965-975.

20. Wehner MF (2013) Very extreme seasonal precipitation in the NARCCAP ensemble: model performance and projections. Climate Dynamics 40: 59-80.

21. Gao YH, Vano JA, Zhu CM, Lettenmaier DP (2011) Evaluating climate change over the Colorado River basin using regional climate models. Journal of Geophysical Research-Atmospheres 116: 12.

22. Lu Y, Kueppers ML (2012) Surface energy partitioning over four dominant vegetation types across the United States in a coupled regional climate model (Weather Research and Forecasting Model 3-Community Land Model 3.5). Journal of Geophysical Research - Atmospheres 117: $1-10$.

23. Rui H, Vollmer B, Teng W, Beaudoing H, Rodell M, et al. (2015) 65 years of reprocessed GLDAS Version 2.0 Data and Their Exploration Using the NASA GES DISC Giovanni.
24. Chen Y, Yang K, Qin J, Zhao L, Tang W, et al. (2013) Evaluation of AMSR-E retrievals and GLDAS simulations against observations of a soil moisture network on the central Tibetan Plateau. Journal of Geophysical Research: Atmospheres 118: 4466-4475.

25. Rodell M, Houser PR, Jambor U, Gottschalck J, Mitchell K, et al. (2004) The global land data assimilation system, Bulletin of the American Meteorological Society 85: 381

26. Kanamitsu M, Ebisuzaki W, Woollen J, Yang SK, Hnilo JJ, et al. (2002) NCEP-DOE AMIP-II reanalysis (R-2). Bulletin of the American Meteorological Society 83: 1631-1643.

27. Verseghy DL, McFarlane NA, Lazare M (1993) CLASS - A canadian landsurface scheme for GCMs: II. Vegettion model and coupled runs. International Journal of Climatology 13: 347-370.

28. Music B, Caya D (2007) Evaluation of the hydrological cycle over the Mississippi River basin as simulated by the Canadian regional climate model (CRCM). Journal of Hydrometeorology 8: 969-988.

29. De Elia R, Caya D, Cote H, Frigon A, Biner S, et al. (2008) Evaluation of uncertainties in the CRCM-simulated North American climate. Climate Dynamics 30: 113-132.

30. Troin M, Caya D, Velazquez JA, Brissette F (2015) Hydrological response to dynamical downscaling of climate model outputs: A case study for western and eastern snowmelt-dominated Canada catchments. Journal of Hydrology: Regional Studies 4: 595-610.

31. Fan FX, Bradley RS, Rawlins MA (2015) Climate change in the Northeast United States: An analysis of the NARCCAP multimodal simulations, Journal of Geophysical Research-Atmospheres 120: 24.

32. Loikith PC, Waliser DE, Lee H, Neelin JD, Lintner BR, et al. (2015) Evaluation of large-scale meteorological patterns associated with temperature extremes in the NARCCAP regional climate model simulations, Climate Dynamics 45: 3257-3274. 